\title{
Entrelacs
}

Cinéma et audiovisuel

$9 \mid 2012$

Voir le genre

\section{La transposition linguistique et culturelle de la série The L Word en France}

\section{Perry Véronique}

\section{(2) OpenEdition}

Journals

Édition électronique

URL : http://journals.openedition.org/entrelacs/361

DOI : 10.4000/entrelacs.361

ISSN : 2261-5482

Éditeur

Éditions Téraèdre

Référence électronique

Perry Véronique, "La transposition linguistique et culturelle de la série The $L$ Word en France », Entrelacs [En ligne], 9 | 2012, mis en ligne le 22 octobre 2012, consulté le 01 mai 2019. URL : http:// journals.openedition.org/entrelacs/361 ; DOI : 10.4000/entrelacs.361

Ce document a été généré automatiquement le 1 mai 2019.

Tous droits réservés 


\title{
La transposition linguistique et culturelle de la série The $L$ Word en France
}

\author{
Perry Véronique
}

$1 \mathrm{Si}$, à l'instar d'Edward Sapir, on pense que «la langue est le guide symbolique de la culture » et qu'elle "conditionne notre vision du monde» (Sapir, 1929), on ne peut occulter l'impact des traductions françaises des dialogues de la série américaine The $L$ Word sur la politique du genre communiquée par ses auteurs. Le titre lui-même joue, comme un reclaimer word ${ }^{1}$ non seulement sur l'allusion à l'insulte, sur le modèle des $F$ Word(s) qui évitent * fuck et ses « dérivés » ou des $C$ Word(s) qui évitent cunt, mais aussi sur le non-dit de l'identification exclusive (en évitant Lesbian). Le choix a été de ne pas le traduire. La raison est à la fois linguistique et culturelle : le jeu de mot est impossible et l'implicite culturel est forcément hermétique pour beaucoup. Pour comprendre, le public doit être initié. Au Québec, la série est devenue Elles, ce qui réduit considérablement le sujet car derrière $L$ se cache bien plus.

2 Cependant, dans les sous-titres et les doublages, les traductions s'imposent. Elles sont certes contraintes par l'espace de l'écran et le rythme des échanges oraux, mais aussi par la morphosyntaxe (imposition de l'opposition masculin/féminin) et les "manques » lexicaux de la langue française dans le domaine du genre ${ }^{2}$. Ces adaptations en français conduisent, par défaut, à des traductions qui colorent les interactions d'une« autre » tonalité, bien plus dépendante d'une «norme duelle» que dans la version originale en anglais, langue où l'on "peut ne pas » sexuer le discours et où la «liberté de genre " repose sur la flexibilité du système linguistique). Ces « écarts de genre » signifient bien plus qu'une absence formelle. Comment, par exemple accepter que la traduction de Human Rights Campaign (littéralement campagne de décence des droits humains) devienne "l'association de défense des droits civils homos "? L'idée que les personnes se battent pour l'égalité des droits n'est pas assimilable à une revendication spécifique fondée sur la notion de « différence ». L'esprit est perdu, la dimension est faussé, l'angle politique n'est pas le même, la transposition est fausse. 
3 Alors comment l'univers de la série, fourmillant de messages et de problématiques sociales, traitant du viol, du transsexualisme, de l'adoption d'enfants, des banques de sperme en libre service pour les lesbiennes, de couples homoparentaux, de couples mixtes, de différence d'âge, d'amours multiples, de bisexualité, de sadomasochisme, de sexe, de genre, de sexualité, de liberté sexuelle, de cancer du sein, d'homophobie, de transphobie, d'hormones, d'expériences divers et variées, d'hommes-lesbiens, comment cet univers transgressif et militant s'arrange-t-il dans la langue-culture française, entre traduction, translation ou trahison? Que reste-il de son message? Quelles responsabilités portent les traductions? Cette analyse sera également illustrée de commentaires trouvés dans des forums de discussions et portant sur les cinq saisons de The L Word (diffusées de 2004 à 2009).

\section{NOTES}

1. Mot qui permet, comme un porte-étendard, de revendiquer des droits à partir du retournement sémantique de l'injure initiale : black et queer sont d'autres exemples.

2. L'emprunt de gay dans la langue courante française est un exemple significatif : il se modèle parfois sur celui de black dans une forme de distanciation salutaire chez les locuteurs francophones.

\section{AUTEUR}

\section{PERRY VÉRONIQUE}

Enseignante (anglais/FLE) et doctorante (didactique de l'anglais/genre). Université de Toulouse 3.

veronique_perry@yahoo.com 